\title{
En torno al derecho moral del autor a la integridad de su obra: reflexiones a propósito del daño efectuado a los murales en el Centro de Lima \\ Regarding the moral right of the authors to the integrity of their work: reflections about the damage done to the murals in the Centre of Lima
}

\section{RAÚL SOLÓRZANO SOLÓRZANO*}

Resumen: Sobre la base del reciente daño efectuado a los murales en el Centro de Lima, a través del presente artículo se analiza el conflicto que puede producirse entre el derecho moral de los autores a la integridad de sus obras y el derecho de propiedad de los titulares del soporte que contiene la creación intelectual. Se brinda criterios a tomarse en cuenta en los conflictos donde estén involucrados murales. Finalmente, se examina las posibles infracciones al derecho moral de integridad.

Palabras clave: derechos de autor - derecho moral de integridad - murales grafitis - obras plásticas

\begin{abstract}
Based on the recent damage done to the murals in the Centre of Lima, this article analyzes the conflict that can occur between the moral right of authors to the integrity of their work and the property rights of the holders of the support containing the intellectual creation. Criteria are provided to analyze conflicts in which murals are involved. Finally, the infringement of moral right of integrity is discussed.
\end{abstract}

Key words: copyright - moral right of integrity - murals - graffiti - artworks

CONTENIDO: I. INTRODUCCIÓN.- II. LOS MURALES Y GRAFITIS ORIGINALES COMO OBRAS PLÁSTICAS SUSCEPTIBLES DE PROTECCIÓN POR EL DERECHO DE AUTOR.- III. DERECHO MORAL DE INTEGRIDAD DE LOS AUTORES DE LOS MURALES.- IV. CRITERIOS A TOMARSE EN CUENTA EN ANÁLISIS DE CONFLICTOS DONDE ESTÉN INVOLUCRADOS MURALES.- IV.1. ORIGEN Y FINALIDAD DEL MURAL.- IV.2. UBICACIÓN DEL MURAL.- IV.3. MATERIAL UTILIZADO Y VOCACIÓN DE PERMANENCIA DEL MURAL.- IV.4. MOTIVO QUE GENERA LA AFECTACIÓN AL DERECHO MORAL DE INTEGRIDAD.V. ANÁLISIS DE POSIBLES INFRACCIONES AL DERECHO MORAL DE INTEGRIDAD.- VI. A MANERA DE CONCLUSIÓN.

* Abogado. Magíster en Derecho con mención en Derecho de la Propiedad Intelectual y de la Competencia por la Pontificia Universidad Católica del Perú (PUCP). Docente a nivel de pregrado y posgrado. Director de la Maestría en Derecho de la Propiedad Intelectual y de la Competencia PUCP. Coordinador del Área de Derecho Mercantil y del Programa de Segunda Especialidad en Derecho de Protección al Consumidor en la Facultad de Derecho PUCP. Correo electrónico: solorzano.rr@pucp.pe 


\section{INTRODUCCIÓN}

La pintura rupestre, surgida en los albores de la humanidad, constituye el antecedente más remoto de la pintura mural. A lo largo de la historia, las civilizaciones utilizaron este arte para diferentes fines. En el Perú, si bien el mural de mayor recordación y exposición es el que contiene la imagen del Señor de los Milagros ${ }^{1}$, podemos encontrar otros ejemplos en las obras del muralista Teodoro Núñez Ureta².

Dado que frecuentemente los murales son elaborados sobre paredes que no le pertenecen al autor, son comunes los conflictos suscitados entre el muralista y el dueño del soporte. Al respecto, Oscar Montezuma ${ }^{3}$ menciona dos situaciones ilustrativas:

- La controversia surgida por la destrucción del mural que Rockefeller Jr. encargó al pintor mexicano Diego Rivera en 1932, obra que iba a formar parte del Radio City Music Hall de Nueva York. El mural fue eliminado porque el pintor incluyó la figura de Lenin.

- En 1962 el escultor Amar Nath Sehgal culminó un gigantesco mural que rodeó un arco central de Vigyan Bhawan, centro gubernamental de la capital de la India. Luego de unas obras de restauración, el mural fue desmontado y puesto en un almacén, lo cual generó una batalla judicial.

El presente artículo surge a partir del intenso debate que originó la repentina, apresurada y muy poco fundamentada acción promovida por la Municipalidad Metropolitana de Lima, encabezada por el alcalde Luis Castañeda Lossio, consistente en eliminar un grupo de murales que habían sido elaborados con el apoyo de la anterior gestión municipal ${ }^{4}$. Dicha eliminación, materializada en el pintado de los coloridos murales con capas monocromáticas, denota un profundo desconocimiento del derecho moral de autor.

\section{LOS MURALES Y GRAFITIS ORIGINALES COMO OBRAS PLÁSTICAS SUSCEPTIBLES DE PROTECCIÓN POR EL DERECHO DE AUTOR}

Los murales son representaciones o imágenes que utilizan muros o paredes como soporte. Dichas imágenes normalmente se realizan con pintura, aunque también pueden utilizarse cerámicos, azulejos,

1 Para conocer mayores antecedentes sobre el origen de este mural, sugerimos revisar: ROSTWOROWSKI, María. Pachacamac y el Señor de los Milagros. Una trayectoria milenaria. Lima: IEP, 1992, pp. 150-151.

2 Al respecto, véase: TORD, Luis Enrique. Teodoro Núñez Ureta. Pintura mural. Lima: Banco Industrial del Perú, 1989

3 MonTEZUMA, Oscar. Murales y derechos de autor (http://www.blawyer.org/2015/03/14/murales-yderechos-de-autor/).

4 Un relato detallado de los hechos puede verse en MURILLO, Javier. Lo que un alcalde se llevó de Lima: crónica de un atentado contra los derechos de autor y los murales perdidos (http://www.parthenon.pe/ privado/mercantil/lo-que-un-alcalde-se-llevo-de-lima-cronica-de-un-atentado-contra-los-derechosde-autor-y-los-murales-perdidos/). 
vidrios de colores, entre otros materiales. En el artículo 2, numeral 8, de la Constitución Política del Perú de 1993, se establece que toda persona tiene derecho «a la libertad de creación intelectual, artística, técnica y científica, así como a la propiedad sobre dichas creaciones y a su producto. El Estado propicia el acceso a la cultura y fomenta su desarrollo y difusión». Por su parte, el decreto legislativo 822 (Ley sobre el Derecho de Autor) señala en su artículo 2, numeral 17, que una obra es «toda creación intelectual personal y original, susceptible de ser divulgada o reproducida en cualquier forma, conocida o por conocerse». Asimismo, sobre el requisito de originalidad, la Sala de Propiedad Intelectual del Tribunal del Instituto Nacional de Defensa de la Competencia y de la Protección de la Propiedad Intelectual (en adelante, INDECOPI), con fecha 23 de marzo de 1998, emitió la resolución 286-1998-TPI-INDECOPI, estableciendo como precedente de observancia obligatoria que «debe entenderse por originalidad de la obra, la expresión (o forma representativa) creativa e individualizada de la obra, por mínima que sea esa creación y esa individualidad. La obra debe expresar lo propio del autor, llevar la impronta de su personalidad ${ }^{5}$.

Asimismo, dentro de los distintos tipos de obra que figuran en el decreto legislativo 822, en el numeral 28 del artículo 2 , se establece que una obra plástica es aquella cuya finalidad apela al sentido estético de la persona que la contempla, como las pinturas, los bocetos, dibujos, grabados y litografías, precisando que las disposiciones específicas sobre este tipo de obras no son aplicables a las fotografías, obras arquitectónicas ni obras audiovisuales. Consecuentemente, un mural, en la medida que cumpla con el requisito de originalidad, puede ser considerado como una obra plástica protegida por el derecho de autor.

En cuanto al grafiti, es frecuente que muchas personas, incluso nuestras autoridades, le atribuyan características de marginalidad ${ }^{6} \mathrm{o}$

5 En dicho precedente se añade lo siguiente: «No será considerado individual lo que ya forma parte del patrimonio cultural (artístico, científico o literario) ni la forma de expresión que se deriva de la naturaleza de las cosas ni de una mera aplicación mecánica de lo dispuesto en algunas normas jurídicas, así como tampoco lo será la forma de expresión que se reduce a una simple técnica o a instrucciones simples que solo requieren de la habilidad manual para su ejecución.

En consecuencia, no todo lo producido con el esfuerzo de su creador merece protección por derechos de autor. Igualmente aun cuando exista certeza de que una creación carente de individualidad ha sido copiada textualmente, tal circunstancia no convierte a esta en obra».

6 Luego del daño que sufrieron los murales del Centro de Lima, el programa «7.3 Noticias» del Canal TV Perú difundió el 19 de marzo de 2015 las declaraciones de la Ministra de Cultura, Diana Alvarez-Calderón, quien textualmente afirmó lo siguiente: «Es que, el grafiti o murales pintados en la ciudad nacen como un arte que viene más bien de la calle, no es un arte que se hace para perdurar. Es lo que yo entiendo del grafiti aquí y en cualquier parte del mundo es casi un arte marginal en su origen porque, digamos, permite a quien hace uso del grafiti expresarse a través de un muro [...]". Posteriormente, cuando la entrevistadora le consulta si el grafiti es arte, la Ministra responde de la forma siguiente: «No estoy diciendo que no sea arte. Digo que, en su origen, el grafiti nace como una expresión que nace de la calle y nace para no perdurar. Es decir, hemos visto grafiteros en el mundo con obras muy importantes, grandes artistas en grandes ciudades y también digamos de la misma manera que acá han sido borrados porque no nacen con el fin de perdurar, digamos, no es la Capilla Sixtina, es arte de la calle, es arte marginal, de protesta de alguna manera pero no es, digamos, patrimonio cultural de la nación" (transcripción de la entrevista que está disponible en: https://www.youtube.com/watch?v=FwAO7NoAltl). Ante dichas

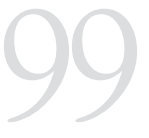

EN TORNO AL

DERECHO MORAL

DEL AUTOR A

LA INTEGRIDAD

DE SU OBRA:

REFLEXIONES A

PROPÓSITO DEL

DAÑO EFECTUADO

A LOS MURALES

EN EL CENTRO DE

LIMA

REGARDING THE

MORAL RIGHT OF

THE AUTHORS TO

THE INTEGRITY

OF THEIR WORK:

REFLECTIONS

ABOUTTHE

DAMAGE DONE

TO THE MURALS

IN THE CENTRE OF

LIMA 
ilegalidad. Al respecto, como señala Rita Amor García, si bien a nivel común, la práctica del grafiti suele ser considerada un acto vandálico e ilegal, actualmente podemos encontrar otras formas de grafiti con intencionalidad artística y estética ${ }^{7}$. En la línea de lo anterior, la citada autora define al grafiti legal como «el realizado como práctica mural, pudiéndose haber hecho con algún tipo de permiso, escrito o verbal, o en lugares donde no queda prohibida la práctica explícitamente, sobre una superficie mural adecuada y encontrándose en la obra una serie de calidades estilísticas propias de un escritor [...] $»^{8}$. Asimismo, en el Diccionario de la Real Academia Española se señala que grafiti o grafito es un «letrero o dibujo circunstanciales, de estética peculiar, realizados con aerosoles sobre una pared u otra superficie resistente».

Tomando en cuenta lo anterior, un grafiti que no cumpla el requisito de originalidad no podría protegerse por el derecho de autor, como sería el caso, por ejemplo, de un grafiti consistente en una simple frase que alabe un equipo de fútbol. Sin embargo, un grafiti sí puede ser considerado como una obra plástica si es que cumple con el requisito de originalidad. Para los efectos del presente artículo, denominaremos murales también a los grafitis originales que se hayan elaborado sobre un muro o pared. A título ilustrativo, a continuación puede apreciarse la imagen del mural realizado por el artista colombiano «Guache», primero en la lista de las obras dañadas en el Centro de Lima9.

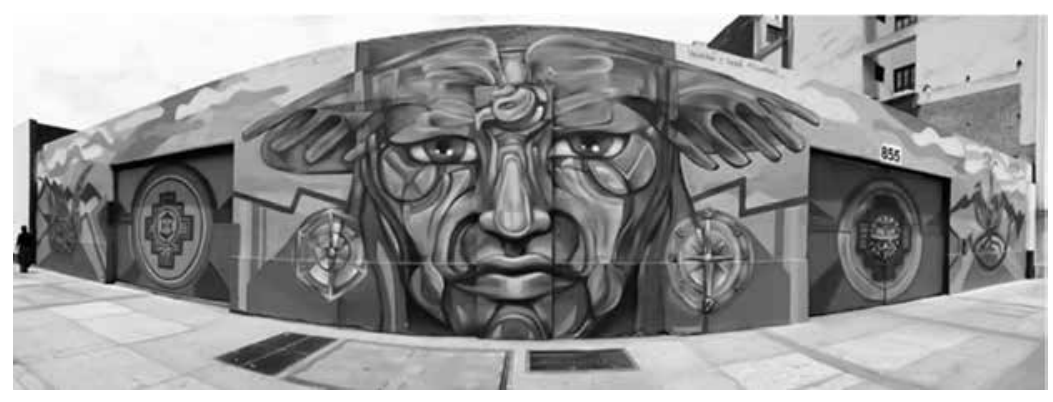

expresiones, el Ministerio de Cultura, a través de su Oficina de Comunicación e Imagen Institucional, tuvo que emitir el siguiente comunicado con fecha 20 de marzo de 2015: «En relación a los recientes sucesos en Lima, el Ministerio de Cultura se reafirma en el principio ineludible de que las expresiones artísticas desempeñan un rol fundamental en la vida y el desarrollo del ser humano y de la sociedad. Por esta razón, se vienen desarrollando acciones que permiten ampliar el acceso a la ciudadanía al ejercicio de sus derechos culturales, a través de la formación, creación, producción, circulación, difusión y disfrute de las manifestaciones culturales como una muestra de su identidad y diversidad.

Desde épocas prehispánicas hasta nuestros días, el arte mural ha sido y continua siendo, un importante medio de expresión de nuestra identidad y cosmovisión.

En tal sentido, el Ministerio de Cultura viene impulsando diferentes iniciativas a nivel nacional para la promoción y acceso a la diversidad de expresiones artísticas, a través de acciones en el espacio público, reafirmando su compromiso con el desarrollo de la cultura y el arte».

7 AmOR García, Rita. Aplicación de la técnica del strappo a la conservación de pinturas realizadas a base de esmaltes sintéticos en aerosol. Arranques de grafitis. Tesis para la obtención del título Máster en Conservación y Restauración de Bienes Culturales, Universidad Politécnica de Valencia (2010-2011), p. 7.

8 Ibídem, p. 10.

9 Imagen disponible en el Facebook oficial del artista "Guache» (https://www.facebook.com/guache. arte/photos/pb.556753197678467.-2207520000.1429432200./842361529117631/?type=3\&theater). En la fuente no aparece el nombre del autor de la fotografía. 


\section{DERECHO MORAL DE INTEGRIDAD DE LOS AUTORES DE LOS MURALES}

Los derechos morales reconocidos en el decreto legislativo 822, a diferencia de los derechos patrimoniales, son perpetuos, inalienables, inembargables, irrenunciables ${ }^{10}$ e imprescriptibles ${ }^{11}$. Asimismo, de acuerdo con el artículo 22, la lista cerrada de derechos morales comprende al de divulgación, paternidad, integridad, modificación o variación, retiro de la obra del comercio y acceso. Nosotros nos concentraremos en el derecho moral de integridad ${ }^{12}$, por medio del cual, el autor ostenta, incluso frente al adquirente del objeto material que contiene la obra, la facultad de oponerse a toda deformación, modificación, mutilación o alteración de la misma ${ }^{13}$.

Sobre el derecho moral de autor, conviene añadir que el Convenio de Berna para la Protección de las Obras Literarias y Artísticas dispone en su artículo 6 bis que, con independencia de los derechos patrimoniales del autor, e incluso después de la cesión de dichos derechos, el autor conservará la facultad de reivindicar la paternidad de la obra y de oponerse a cualquier deformación, mutilación u otra modificación de la misma o a cualquier atentado a la misma que cause perjuicio a su honor o a su reputación. Asimismo, la Decisión 351 (Régimen Común Andino sobre Derecho de Autor y Derechos Conexos) establece en su artículo 11, inciso c, que el autor tiene el derecho inalienable, inembargable, imprescriptible e irrenunciable de oponerse a toda deformación, mutilación o modificación que atente contra el decoro de la obra o la reputación del autor.

En el caso de las obras plásticas donde generalmente nos encontramos ante ejemplares únicos e irrepetibles, no siempre la persona que tiene la titularidad de la creación intelectual (corpus mysticum) es la misma que ostenta la propiedad del soporte que la contiene (corpus mechanicum). Esta problemática se aborda en el segundo párrafo del artículo 3 del decreto legislativo 822 al indicar que los derechos reconocidos en la norma son independientes de la propiedad del objeto material en el cual está incorporada la obra.

Sobre el derecho moral de integridad, Ricardo Antequera sostiene acertadamente que «la faceta más dramática del derecho de integridad está referida a la conservación del soporte único que contiene la obra, como en las artes plásticas, porque como ha señalado la Sala $1^{\text {a }}$ del

10 Si bien no es objeto de la presente investigación analizar la conveniencia de mantener un sistema de derechos morales irrenunciables, cabe señalar que en países como Reino Unido y Canadá es posible efectuar dicha renuncia bajo ciertos criterios.

11 Artículo 21 del decreto legislativo 822.

12 En el presente artículo no abordaremos a los derechos patrimoniales de autor. Sobre dicho tema, sugerimos revisar BERCOVITZ, Germán. Obra plástica y derechos patrimoniales de su autor. Madrid: Tecnos, 1997.

13 Artículo 25 del decreto legislativo 822.

EN TORNO AL

DERECHO MORAL

DEL AUTOR A

LA INTEGRIDAD

DE SU OBRA:

REFLEXIONES A

PROPÓSITO DEL

DAÑO EFECTUADO

A LOS MURALES

EN EL CENTRO DE

LIMA

REGARDING THE

MORAL RIGHT OF

THE AUTHORS TO

THE INTEGRITY

OF THEIR WORK:

REFLECTIONS

ABOUTTHE

DAMAGE DONE

TO THE MURALS

IN THE CENTRE OF

LIMA 
Tribunal Supremo español, su destrucción es el atentado más grave, por irreformable, que pueda inferirse al derecho moral de respeto a la obra» ${ }^{14}$. En el caso de los murales del Centro de Lima, sus autores, pese a no ser propietarios de las paredes sobre las cuales se hicieron las correspondientes creaciones, son indudablemente titulares de derechos morales.

\section{CRITERIOS A TOMARSE EN CUENTA EN ANÁLISIS DE CONFLICTOS DONDE ESTÉN INVOLUCRADOS MURALES}

Cuando estamos frente a ejemplares únicos de obras plásticas, como es el caso de los murales, pueden producirse controversias entre el propietario del soporte y el creador de la obra. Ante ello, coincidimos con la doctrina que de forma unánime señala que en este tipo de casos no puede establecerse un derecho preferente en dicho conflicto sino que debe encontrarse un justo equilibrio luego de la ponderación correspondiente $^{15}$, utilizando para ello diferentes criterios. A continuación señalaremos cuatro criterios que consideramos podrían tomarse en cuenta en el caso puntual del análisis de murales.

\section{IV.1. Origen y finalidad del mural}

El origen del mural puede ser de la más diversa índole.

a) Mural elaborado sin autorización en una propiedad pública o privada. Este sería el caso de la elaboración subrepticia, durante la noche, de un mural que cumpla con el requisito de originalidad.

b) Mural elaborado por encargo en una propiedad pública o privada. En este supuesto podría haberse pactado la transferencia de la titularidad de los derechos patrimoniales. Sin embargo, tal como señala el artículo 16 del decreto legislativo 822, a falta de acuerdo contractual expreso, se tendría que presumir que los derechos patrimoniales sobre el mural han sido cedidos al comitente en forma no exclusiva y en la medida necesaria para sus actividades habituales en la época de la creación, lo cual también implica que el comitente puede divulgar la obra y defender los derechos morales en cuanto sea necesario para su explotación.

14 ANTEQUeRA PARILLI, Ricardo. Estudios de derecho de autor y derechos afines. Madrid: Reus, 2007, p. 89. 15 LÓPEZ RICHART, Julián. Derecho de autor e intangibilidad del espacio público. En Matilde Cuena Casas \& otros (coords.). Estudios de derecho civil en homenaje al profesor Joaquín José Rams Albesa. Madrid: Dykinson, 2013, p. 962; VIDAL PORTABALES, Ignacio. Comentario a la Sentencia de la AP de Alicante (Sección 8a) de 11 de marzo de 2011. Núm. 112/2011 (AC/2011/1159). Sobre la vulneración del derecho a la integridad de la obra plástica por cambio del contexto espacial y otras cuestiones. Actas de derecho industrial y derecho de autor, 32 (2011-2012), p. 588; ANTEQUERA PARILLI, Ricardo. Estudios de derecho industrial y derecho de autor (Análisis de jurisprudencia comparada). Bogotá: Pontificia Universidad Javeriana/Temis, 2009, p. 502. 
Este podría ser el origen de los murales en el Centro de Lima. En efecto, durante el mes de marzo de 2013 se realizó en nuestra ciudad el Festival Internacional de Arte Urbano Latido Americano con la presencia de artistas urbanos nacionales e internacionales. Este evento contó con el apoyo de la Municipalidad Metropolitana de Lima ${ }^{16}$.

En cuanto a la finalidad de la obra, podemos hallar las siguientes alternativas.

a) Mural con finalidad puramente estética o de embellecimiento. Este sería el caso de los murales decorativos que se encargan pintar en algunas salas o habitaciones de casas.

b) Mural con finalidad comercial. Por ejemplo, un mural pintado al interior de un centro comercial, con cuyo contenido se persiga fomentar el consumo de bienes y servicios. No debe confundirse con un afiche publicitario pues el mural constituye un ejemplar único.

c) Mural con finalidad de brindar algún tipo de mensaje. A través del contenido del mural, el autor podría querer brindar, por ejemplo, un mensaje de crítica social o apoyo a una causa determinada.

\section{IV.2. Ubicación del mural}

Bajo este criterio, podemos encontrar dos situaciones.

a) Mural elaborado sin tomar en cuenta cuál será su ubicación final. Por ejemplo, un mural hecho en un soporte móvil que permitirá adherirlo a cualquier pared.

b) Mural elaborado tomando en cuenta su ubicación en un lugar específico, también conocido como site specific art.

Sobre este criterio, debe considerarse que el muralista podría haber concebido su obra en virtud de su ubicación o de su entorno de destino final. En tal sentido, es pertinente resaltar la existencia de dos recientes pronunciamientos en España vinculados al análisis de la posible vulneración de derechos morales de integridad en el caso de dos esculturas que fueron elaboradas para ser ubicadas en un lugar específico.

\section{a) Escultura «La Patata»}

El Ayuntamiento de Amorebieta-Etxano (Vizcaya, País Vasco, España) encargó al artista Andrés Nagel Tejada la elaboración de una escultura en bronce en el año 2002, la cual se conoce comúnmente como

16 Aunque no figuraban en él las condiciones exactas de participación en el Festival, el sitio web de la Municipalidad (http://www.limacultura.pe/patrimonio/fotos/latidoamericano-festival-internacional-dearte-urbano) ofrecía mayor información sobre el mencionado festival. Cabe notar, sin embargo, que el enlace citado ha sido desactivado por la actual gestión de la Municipalidad de Lima.

ENTORNO AL DERECHO MORAL

DEL AUTOR A

LA INTEGRIDAD

DE SU OBRA:

REFLEXIONES A

PROPÓSITO DEL

DAÑO EFECTUADO

A LOS MURALES

EN EL CENTRO DE

LIMA

REGARDING THE

MORAL RIGHT OF

THE AUTHORS TO

THE INTEGRITY

OF THEIR WORK:

REFLECTIONS

ABOUTTHE

DAMAGE DONE

TO THE MURALS

IN THE CENTRE OF

LIMA 
«La Patata». Se pactó expresamente que se ubicaría en una rotonda central del cruce de unas conocidas calles. Años después, como resultado de una modificación urbanística, se planificó retirar la escultura, ante lo cual el autor, basándose en el artículo 14 de la Ley de la Propiedad Intelectual ${ }^{17}$, alegó que el derecho moral a la integridad también involucraba la no alteración de la ubicación para la cual se concibió la obra originalmente.

El caso llegó hasta el Tribunal Supremo de España, el cual declaró, mediante sentencia 458/2012 de fecha 18 de enero de 2013, que si bien el derecho moral a la integridad comprende que no se modifique la ubicación de la obra, «no ha lugar a prohibir la modificación de su emplazamiento de forma absoluta y en ninguna circunstancia, debiendo en cada caso ponderarse los intereses concurrentes» ${ }^{18}$. Este pronunciamiento es particularmente importante pues dicha instancia estableció los siguientes criterios en su considerando 40:

El derecho del autor de la obra plástica, creada para ser colocada en un lugar específico, comprende el derecho a que no se modifique su ubicación.

La alteración del lugar de ubicación vulnera el derecho del autor a la integridad de la obra y afecta a sus legítimos intereses, aunque se exhiba en condiciones que no supongan un perjuicio a su reputación.

La integridad de la obra creada para un lugar específico no se vulnera necesariamente cuando se sitúa en otra ubicación, si la modificación del emplazamiento no interfiere en el proceso de comunicación entre el artista mediante su obra y la comunidad.

El derecho del autor a la integridad de la obra puede comportar el de que no se exhiba en una ubicación distinta a aquella para la que fue creada, pero no es absoluto.

El derecho del autor, al igual que el del propietario del soporte material, debe ejercitarse de buena fe, de forma no abusiva ni anómala y debe coordinarse con los del propietario del soporte material y los de la comunidad.

La decisión en supuesto de conflicto debe ser el resultado de la ponderación del caso concreto (las cursivas son nuestras).

17 Para el análisis del presente caso y de las demás sentencias españolas, debe tomarse en cuenta que existen ciertas diferencias entre la normativa del derecho moral de integridad en Perú y España. En efecto, el artículo 14 de la Ley de Propiedad Intelectual de España, en lo que se refiere al derecho moral, señala que corresponden al autor los siguientes derechos irrenunciables e inalienables: «[...] 4. Exigir el respeto a la integridad de la obra e impedir cualquier deformación, modificación, alteración o atentado contra ella que suponga perjuicio a sus legítimos intereses o menoscabo a su reputación" (las cursivas son nuestras).

18 Segundo extremo del fallo de la Sentencia del Tribunal Supremo español de fecha 18 de enero de 2013. 
b) Escultura «Monumento al Pescador»

En 1988 el Ayuntamiento de El Campello (Alicante, España) encargó al artista plástico Arcadi Blasco la elaboración de un conjunto escultórico denominado «Monumento al Pescador», el cual consta de dos partes que representan un timón y una proa, estando una en el mar y otra en tierra, a su vez unidas por un haz de luz. Posteriormente, ante el cambio de las condiciones originales de la zona circundante a la creación - la parte que estaba en el mar pasó a estar al medio de la arena pues se ejecutaron obras de regeneración de la playa-, se demandó al Ayuntamiento por vulneración del derecho moral de integridad del escultor. El Ayuntamiento contestó señalando que las obras efectuadas en la playa respondían a un tema de interés público.

El caso llegó a la Audiencia Provincial de Alicante que, mediante sentencia de fecha 11 de marzo de 2011, declaró que el Ayuntamiento de El Campello infringió el derecho moral a la integridad de la obra del escultor al no haber cumplido con su deber de conservación ni de salvaguarda de la concepción artística del conjunto escultórico, condenándolo a la reparación de las partes dañadas y a una indemnización económica a favor del escultor. Al respecto, Julián López sostiene que la Audiencia Provincial de Alicante, en concordancia con la doctrina de las modificaciones indirectas, considera que la alteración del entorno sí puede suponer una violación del derecho a la integridad, siempre que implique la desnaturalización de la obra, es decir, cuando quede desvirtuada la concepción artística que el autor pretendía trasmitir con ella, pues se apreciaría un perjuicio del legítimo interés o un menoscabo de la reputación del autor ${ }^{19}$.

\section{IV.3. Material utilizado y vocación de permanencia del mural}

Considerando el material usado en su elaboración, caben las siguientes opciones.

a) Mural elaborado con material durable como pintura, spray, cerámico, etcétera.

b) Mural hecho con material poco durable, por ejemplo tiza o carboncillo.

Asimismo, por la vocación de permanencia, normalmente podemos hallar dos tipos de murales.

a) Mural con vocación de alta permanencia. Por lo general este es el caso de los murales que encargan elaborar las instituciones públicas en zonas interiores. Suelen permanecer durante décadas

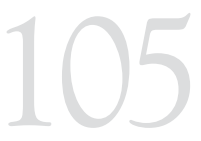

EN TORNO AL

DERECHO MORAL

DEL AUTOR A

LA INTEGRIDAD

DE SU OBRA:

REFLEXIONES A

PROPÓSITO DEL

DAÑO EFECTUADO

A LOS MURALES

EN EL CENTRO DE

LIMA

REGARDING THE

MORAL RIGHT OF

THE AUTHORS TO

THE INTEGRITY

OF THEIR WORK:

REFLECTIONS

ABOUTTHE

DAMAGE DONE

TO THE MURALS

IN THE CENTRE OF

LIMA 
en razón de costos y dimensiones. A modo de ejemplo, tenemos el famoso mural de Teodoro Núñez Ureta denominado «La educación en el Perú», el cual mide 3,10 metros de ancho por 35 metros de largo y se ubica al interior de la antigua sede del Ministerio de Educación.

b) Mural con vocación de baja permanencia. Este podría ser el caso de los murales realizados bajo el contexto de un festival o de un concurso. Al respecto, hay dos casos ilustrativos:

- En el año 2014, la Municipalidad de Villa El Salvador promovió un concurso titulado «Murales y graffiti para la prevención de la violencia y criminalidad», indicando en las bases que «el tema motivador del concurso es por una ciudad segura a favor de las mujeres y jóvenes sin violencia y discriminación con oportunidades y mejora de los espacios públicos» ${ }^{20}$. Cabe señalar que no se indica el tiempo de permanencia de las obras ni el destino que tendrán las mismas luego de transcurrido cierto tiempo.

- A la fecha de culminación del presente artículo, la Municipalidad de Barranco venía organizando un concurso de murales denominado «Las paredes hablan» en cuyas bases se señala que:

(...) el tema del proyecto de mural es libre pero se tendrán en mayor consideración los mensajes referidos a Barranco, su historia, cultura y tradición como temática a abordarse. Los proyectos presentados no deberán contener contenido político si este está dirigido de manera explícita hacia una persona, entidad o empresa de carácter específico (tanto del sector público como privado) y tampoco serán admitidas las propuestas con mensajes que promuevan la discriminación de ningún sector de la sociedad civil (es decir, no serán admitidos contenidos racistas, sexistas o de discriminación religiosa, etcétera) por atentar contra los objetivos y la filosofía del concurso ${ }^{21}$.

Advertimos que en este concurso sí se indica expresamente en las bases que los trabajos a ser ejecutados se mantendrán por un tiempo mínimo de dos años, luego de lo cual se realizará una segunda edición y se podría disponer nuevamente de algunos de los muros. Sin embargo, al no mencionarse cuál será el destino de los murales originales, no se tiene conocimiento si serán retirados o si se borrarán para dar paso a los del siguiente concurso.

20 Para consultar las bases, véase: http://munives.gob.pe/contenidos/pdf/BASES\%20DEL\%20 CONCURSO\%20FINAL.pdf

21 Las bases pueden consultarse en http://www.munibarranco.gob.pe/images/pdf/bases.pdf 
Si bien verificamos que en este segundo supuesto los murales podrían tener un tiempo de exhibición de unos pocos años, ello no implica que, como explicaremos más adelante, puedan ser borrados o destruidos sin que se hayan realizado previamente determinadas acciones en resguardo del derecho moral del autor a la integridad de su obra. Asimismo, sugerimos que en los concursos y festivales de murales que organicen las Municipalidades, se incluya en las bases una fase de aprobación del boceto, el tiempo de exposición del mural y la recomendación de efectuar la obra en un «soporte móvil ${ }^{22}$ que permita que posteriormente su autor pueda llevarse el mural sin deterioro.

Comentando otros ámbitos artísticos, es diferente el caso de la exhibición itinerante de esculturas de vacas pintadas, conocidas como Cow Parade ${ }^{23}$, pues su vocación de permanencia es muy breve por la naturaleza de sus fines. Lo mismo pasa con las populares esculturas realizadas en arena ${ }^{24} \mathrm{O}$ en hielo, dado el material empleado en su elaboración.

\section{IV.4. Motivo que genera la afectación al derecho moral de integridad}

Pueden ser múltiples los motivos que ponen en riesgo el derecho moral del autor a la integridad de su obra. A continuación, presentamos dos casos ilustrativos.

\section{a) Puente «Zubi Zuri»}

El Ayuntamiento de Bilbao (Vizcaya, País Vasco, España) fue demandado por el arquitecto Santiago Calatrava por haber vulnerado su derecho moral a la integridad, al haber modificado la estructura del puente que el autor había diseñado. En efecto, el Ayuntamiento autorizóla modificación del puente original (conocido como «Zubi Zuri»), así como la conexión con una nueva estructura diseñada por un arquitecto distinto.

Mediante sentencia del Juzgado de lo Mercantil número 1 de Bilbao del 23 de noviembre de 2007, se reconoció que la remoción de una parte del puente Zubi Zuri y su conexión con otro puente constituye una alteración en la obra del arquitecto Calatrava, pero la utilidad pública del anexo debía prevalecer sobre el interés privado del autor ${ }^{25}$.

$22 \mathrm{Al}$ respecto, sugerimos revisar la siguiente página web donde el artista español Eduardo Zamarro describe detalladamente la técnica de soporte móvil para pintura mural (http://www.eduardozamarro. $\mathrm{com} / \mathrm{blog} / ? \mathrm{p}=678$ )

23 De acuerdo con la información disponible en www.cowparade.com, estamos ante el más amplio y exitoso evento de arte público del mundo. Dicha exhibición, creada en 1999, ha recorrido 79 ciudades alrededor del mundo.

24 Existen en el Perú diversas Municipalidades que promueven en la estación de verano concursos de esculturas de arena.

25 EsPín ALBA, Isabel. Derecho moral del arquitecto: el caso Calatrava (Comentario a la Sentencia del Juzgado de lo Mercantil número 1 de Bilbao, de 23 de noviembre de 2007). Actas de derecho industrial y derecho de autor, 28 (2007-2008), p. 669.

ENTORNO AL

DERECHO MORAL

DEL AUTOR A

LA INTEGRIDAD

DE SU OBRA:

REFLEXIONES A

PROPÓSITO DEL

DAÑO EFECTUADO

A LOS MURALES

EN EL CENTRO DE

LIMA

REGARDING THE

MORAL RIGHT OF

THE AUTHORS TO

THE INTEGRITY

OF THEIR WORK:

REFLECTIONS

ABOUTTHE

DAMAGE DONE

TO THE MURALS

IN THE CENTRE OF

LIMA 
En tal sentido, en dicha sentencia se indicó que, pese a la alteración de la obra, no se había vulnerado el derecho a la integridad del autor, desestimándose la demanda. Sin embargo, este pronunciamiento fue revocado por la Audiencia Provincial de Vizcaya mediante sentencia de fecha 10 de marzo de 2009, a través de la cual se consideró que el Ayuntamiento de Bilbao vulneró el derecho moral del arquitecto Calatrava, condenándosele a un pago de indemnización de 30 mil euros $^{26}$.

En este punto es pertinente aclarar que, de conformidad con el artículo 80 del decreto legislativo 822, en el Perú el autor de obras arquitectónicas no puede oponerse a las modificaciones que se hicieren necesarias durante la construcción o con posterioridad a ella, o a su demolición. Incluso se añade en dicha disposición que, si las modificaciones se hiciesen sin su consentimiento, el autor podrá repudiar la paternidad de la obra modificada y el propietario quedará prohibido de invocar en el futuro el nombre del autor del proyecto concebido inicialmente.

\section{b) Murales en La Coruña}

Con fecha 6 de noviembre de 2006, el Tribunal Supremo de España, mediante la resolución 1082/2006, se pronunció acerca del daño efectuado a unos murales que habían sido originalmente elaborados en virtud de un concurso. Efectivamente, cuando la Cooperativa Agraria Provincial de La Coruña, propietaria del edificio donde se efectuaron los murales, vendió el predio a Restauraciones Monumentales y Construcciones S.A., la nueva titular procedió a eliminar las pinturas. Esto generó una demanda que llegó hasta la máxima instancia, quien pese a reconocer que la demolición del muro en que se encuentra una obra puede constituir una violación del derecho moral de autor, consideró que en el presente caso había una justificación que excluía su ilicitud. En concreto, el Tribunal Supremo señaló que «son singularmente relevantes las circunstancias del muro y del edificio, cuya situación de deterioro exigía la reconstrucción, de la que no cabía prescindir sin riesgo para la seguridad de las personas, resultando imposible la conservación de las pinturas» ${ }^{27}$.

\section{ANÁLISIS DE POSIBLES INFRACCIONES AL DERECHO MORAL DE INTEGRIDAD}

Tomando en cuenta los criterios expuestos en el punto precedente (aunque considerando que las combinaciones pueden dar lugar a múltiples casos), a continuación ensayaremos algunas soluciones a

26 Gómez SEGADE, José Antonio. La sentencia de apelación sobre el puente de Calatrava. Un paso atrás en la relación entre el derecho moral del arquitecto y el interés público. Actas de derecho industrial y derecho de autor, 29 (2008-2009), p. 1483.

27 Considerando 5 de la resolución 1082/2006 del Tribunal Supremo de España. 
circunstancias hipotéticas. Es sumamente importante resaltar que, en cualquiera de las situaciones que analizaremos en esta sección, a efectos de no vulnerar el derecho moral del autor a la integridad de su obra, el propietario del soporte debe previamente actuar con una mínima diligencia contactando al autor o a sus herederos, o en todo caso realizando algún tipo de registro fotográfico, como explicaremos más adelante.

a) Mural hecho subrepticiamente, sin permiso. Consideramos que estaríamos ante una situación de mala fe y abuso del derecho si quien realiza un mural sin autorización alguna se opone a la destrucción de su obra. En este caso, al eliminarse el mural que el titular del soporte jamás consintió, no parece que podamos considerar que se ha vulnerado el derecho moral de integridad del autor.

b) Mural que modifica el bosquejo que inicialmente había sido aprobado. Imaginemos que se encarga a un muralista hacer una obra en las paredes interiores y exteriores del nuevo Lugar de la Memoria en Miraflores, indicándole que en su obra no puede colocar imágenes que constituyan apología del terrorismo. Para mayor certeza, incluso se llega a aprobar un boceto del mural. Sin embargo, pese a la instrucción expresa, el autor hace todo lo contrario $^{28}$. Aquí la eliminación del mural no debería generar una infracción al derecho moral de integridad.

c) Mural hecho por encargo pero que luego debe eliminarse. Consideramos que el titular del soporte podría justificar su acción en virtud de la salvaguarda del interés público. Ello podría ilustrarse con dos supuestos:

- destrucción de un mural situado en una pared muy antigua de una edificación municipal que está a punto de desplomarse en la calle;

- destrucción de un mural situado en medio de un parque que quedó dañado luego de un terremoto, para dar paso a la colocación de una pileta.

En este punto es ilustrativo citar a Julián López quien, refiriéndose al caso de la escultura «Monumento al Pescador», indica que la Audiencia Provincial de Alicante en su sentencia de 11 de marzo de 2011 «entiende que la presencia de un interés público no exime al juzgador de la necesidad de proceder a ponderar el resto de circunstancias concurrentes para poder determinar si el autor está obligado a soportar la alteración de su obra» ${ }^{29}$.

ENTORNO AL

DERECHO MORAL

DEL AUTOR A

LA INTEGRIDAD

DE SU OBRA:

REFLEXIONES A

PROPÓSITO DEL

DAÑO EFECTUADO

A LOS MURALES

EN EL CENTRO DE

LIMA

REGARDING THE

MORAL RIGHT OF

THE AUTHORS TO

THE INTEGRITY

OF THEIR WORK:

REFLECTIONS

ABOUTTHE

DAMAGE DONE

TO THE MURALS

IN THE CENTRE OF

LIMA 


\section{d) Cambio de ubicación de un mural}

- Mural hecho sin considerar lugar de ubicación final. Consideramos que podría cambiarse de ubicación sin vulnerar el derecho moral de integridad de su autor. Tal sería el caso de un mural de temática libre, donado a una Municipalidad que estima cambiar su ubicación cada cierto tiempo con motivo de exhibición itinerante.

- Mural hecho considerando su ubicación en lugar específico, al cual se le cambia de sitio. Imaginemos que una Municipalidad contrata a un artista para elaborar un mural que se colocará en medio del parque Baden-Powell, fundador del Movimiento Scout Mundial, solicitándole que incluya imágenes alusivas a dicha organización. Si, posteriormente, la Municipalidad muda el mural a otro parque que había sido construido en honor de un personaje que por algún motivo estaba abiertamente en contra del Movimiento Scout, consideramos que estaríamos ante una infracción al derecho moral de integridad. Dependiendo de la circunstancia concreta, distinto sería el caso de un cambio en la ubicación del mural por razones justificadas de interés público.

- Mural hecho considerando su ubicación en lugar específico, al cual se le modifica el entorno. Imaginemos que la siguiente fotografía $^{30}$ corresponde a un mural ubicado en una pared que circunda un parque municipal:

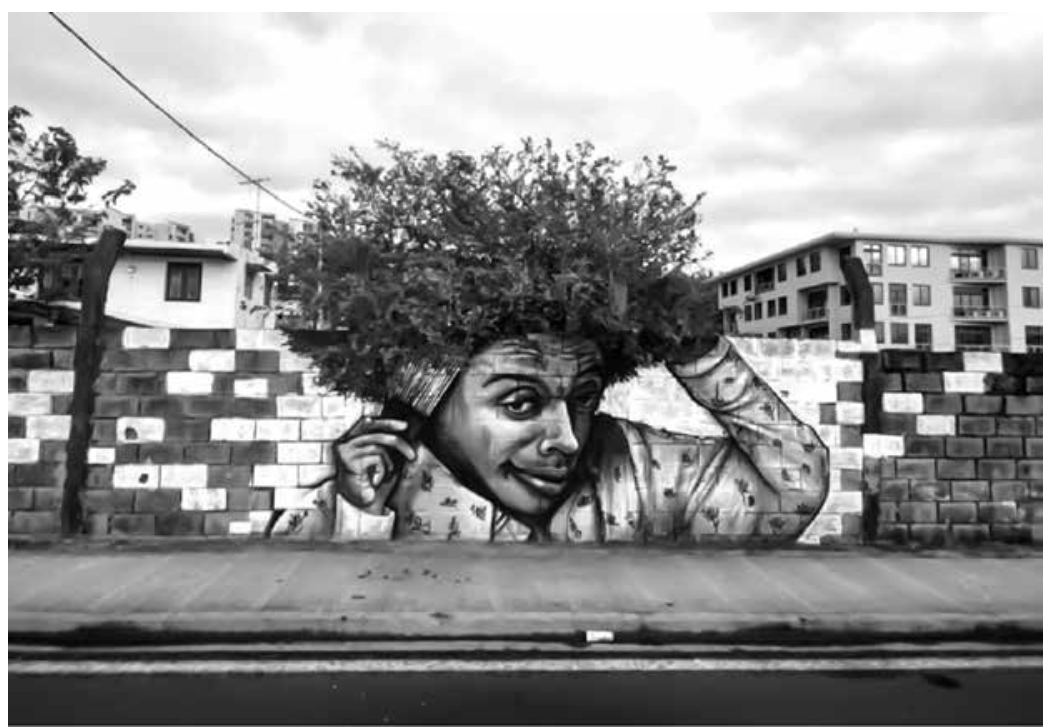

30 La imagen ha sido extraída del sitio web: http://kristianeliz.com/nuxuno-xan/. En dicha fuente se indica que la fotografía ha sido tomada por Kristian Eliz y corresponde a un mural del artista Nuxuno Xän, ubicado en Fort De France, Martinique, Francia. 
Como puede apreciarse, el autor concibió su obra tomando como base el árbol que sobresale del parque, complementándolo con la imagen de un hombre que peina su abundante cabellera. Ante ello, si la Municipalidad decide cortar el árbol sin ninguna justificación, consideramos que estaríamos frente a una vulneración al derecho moral de integridad ya que la obra habría perdido completamente su razón de ser.

En resguardo de los derechos morales del autor, consideramos que el propietario del soporte debería, con suficiente anticipación, contactar al autor o sus herederos para que puedan llevarse la obra. Sin embargo, hay que tomar en cuenta que, a diferencia de las esculturas, en el caso de los murales normalmente no resulta fácil llevarse la obra porque se encuentra adherida a un muro o pared. Ante ello, el autor o sus herederos podrían utilizar alguna técnica de arranque de pintura mural, lo cual permite su traslado. De acuerdo con Rita Amor García, se conocen en la historia tres tipos de arranques: el stacco a massello, el stacco y el strappo ${ }^{31}$. Si el mural cuenta con relieves, se podría optar por un escaneo en tres dimensiones. De no ser factible contactar al autor o a sus herederos, el propietario del soporte podría realizar un registro fotográfico o fílmico de la obra.

Con relación al daño efectuado a los murales en el Centro de Lima, estimamos que los responsables han vulnerado el derecho moral de los autores a la integridad de sus obras, por lo que deberían ser sancionados ejemplarmente por la Comisión de Derecho de Autor del INDECOPI. Ello tomando en cuenta, entre otros factores, que los murales se elaboraron con total consentimiento, que no hay razones sólidas que justifiquen el daño perpetrado y que no se adoptó ningún tipo de medida diligente que hubiese permitido a los autores retirar sus obras de los muros o, al menos, realizar algún tipo de reproducción o registro especial.

\section{A MANERA DE CONCLUSIÓN}

Como hemos visto a lo largo del presente artículo, no es posible establecer un derecho preferente ante el conflicto que puede producirse entre el derecho moral del autor a la integridad de su obra y el derecho de propiedad del titular del soporte que contiene la creación intelectual. En el caso de murales, ejemplares únicos de obras plásticas, pueden aplicarse los criterios esbozados en el presente trabajo (origen, finalidad, ubicación, material utilizado, vocación de permanencia y motivo de la afectación) con miras a lograr un equilibrio luego de la ponderación correspondiente.

ENTORNO AL

DERECHO MORAL

DEL AUTOR A

LA INTEGRIDAD

DE SU OBRA:

REFLEXIONES A

PROPÓSITO DEL

DAÑO EFECTUADO

A LOS MURALES

EN EL CENTRO DE

LIMA

REGARDING THE

MORAL RIGHT OF

THE AUTHORS TO

THE INTEGRITY

OF THEIR WORK:

REFLECTIONS

ABOUTTHE

DAMAGE DONE

TO THE MURALS

IN THE CENTRE OF

LIMA 
Adicionalmente a la sanción que la instancia pertinente del INDECOPI debería imponer, consideramos que nos encontramos ante una estupenda oportunidad para que la Sala de Propiedad Intelectual del Tribunal de dicha institución, en la eventualidad que tenga que pronunciarse sobre el presente caso, emita y publique un precedente de observancia obligatoria con relación a los alcances generales del derecho moral de integridad.

Finalmente, recogiendo lo abordado en el presente trabajo, sugerimos que en el capítulo correspondiente a derechos morales del decreto legislativo 822 se incorpore el siguiente artículo:

Si el titular del soporte que contiene una obra de arte de ejemplar único tuviese que realizar algún acto que pusiese en riesgo el derecho moral del autor a la integridad de su obra (alteración, daño, destrucción, cambio de ubicación, entre otras modalidades), deberá previamente comunicarlo por escrito al autor o a sus herederos para que puedan llevarse la obra en un plazo máximo de 30 días hábiles contados a partir de la comunicación. De no ser posible llevarse la obra, el autor o sus herederos podrán reproducirla dentro del mismo plazo. En caso de no poder ubicar al autor o a sus herederos, el titular del soporte que contiene la obra, antes de poner en riesgo el derecho moral del autor, deberá tomarle fotografías digitales desde distintos ángulos, así como a su entorno de ubicación y enviarlas por medio de correo electrónico al INDECOPI para su conservación en un repositorio que la institución creará para tal fin. En dicho mensaje, el remitente deberá indicar su nombre completo, dirección, teléfono y, de saberlo, el nombre del autor de la obra en cuestión. 